\title{
DESIGN AND ANALYSIS OF CAR CHASSIS
}

\section{AJAY BANGAR, MUGDHA SHRIVASTAVA, RAJAN SHARMA \& TRAPTI SHARMA}

\author{
Assistant Professor, RJIT Tekanpur, Madhya Pradesh, India
}

\begin{abstract}
This work is a step to find out the best optimized design of a car chassis taking material of pipe, pipe diameter and the thickness of pipe as prime parameter. We have accomplished this stress analysis, with the help of ANSYS software and Taguchi methodology. The Stress analysis of the car chassis will fit all aspects and concepts according to the rules of Marathon Challenge. The objective of this project is to design best car chassis. We did this to avoid any possibilities of failure in the structure and also to provide an enough stronger supporting member to make the chassis stronger in terms of deformation. After making the frame, we analyzed it for compressive stress due to the impact loading and identified the region of maximum stress and its possible value. We did the same procedure for nine combinations of material, thickness and diameter according to orthogonal array and observed the induced stress. We predicted that the $M_{3}+T_{3}+D_{3}$ will give the optimum result of induced stress. We checked the stress for $M_{3}+T_{3}+D_{3}$ and found it satisfactory. Finally, we derived a mathematical model for inducing stress for impact loading with the help of MATLAB software. Result of induced stress both from ANSYS and mathematical models are same.

KEYWORDS: Chassis Design, ANSYS, Impact Forces, Matlab, Taguchi Method
\end{abstract}

Received: Jun 07, 2017; Accepted: Jun 25, 2017; Published: Jul 12, 2017; Paper Id: IJMPERDAUG201713

\section{INTRODUCTION}

The chassis is like a skeleton of car body, which give support to the outer body, engine and other elements of the vehicle. Design of chassis depends upon load of the vehicle and the limit of maximum speed of the vehicle. Force considered on the chassis always is equal to the rate of change of momentum of the body during the impact. During the collision of vehicle, maximum stress induced in chassis is crushing stress. We have taken pipes of different material, thickness and diameter to make chassis of small cars (Quad bike)

\section{Objectives}

The objectives of the paper are as follows:

- The selection of material for chassis.

- To construct the appropriate chassis

- To determine the maximum stress concentration areas. 


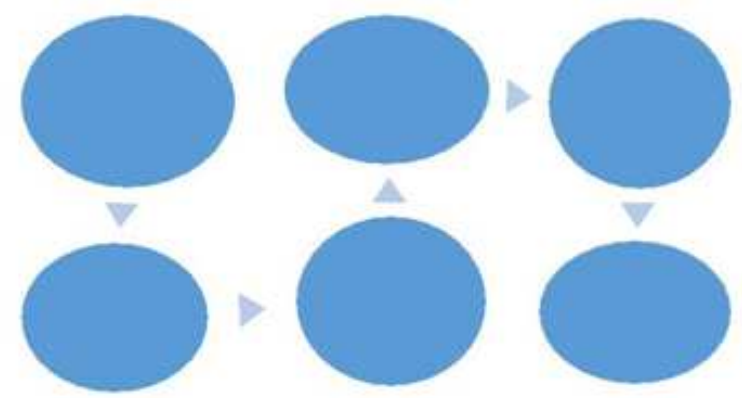

Figure 1.1: A Model of CAD

Table 1

\section{Chassis}

\begin{tabular}{|l|l|l|l|}
\hline 3D CAD & \multirow{2}{*}{ DESIGN } & & \\
\cline { 3 - 4 } MODELLING & & ELEMENTAL & \\
\hline & & ANALYSIS & \\
\hline & ANALYTICAL & & \\
\hline \multirow{2}{*}{ MATERIAL } & CALCULATIO & & \\
\cline { 2 - 4 } & NS & CONCLUSIO & \\
\cline { 3 - 4 } SELECTION & & $\mathrm{N}$ & \\
\cline { 2 - 4 } & & & \\
\hline
\end{tabular}

The chassis is a skeleton frame made up of pipes and other materials of various cross sections.

The chassis must consist of stability, torsional rigidity, as well as it should have a relatively high degree of flexibility, as there is no suspension. It can also be an adequate strength to sustain a load of operator and other accessories. The chassis is designed with convenience and safety for operators. The chassis was designed for a safe ride and the load is applied to it without compromising the structural strength.

\section{METHODOLOGY}

This technique is completely based on statistical concepts. Many renowned firms have achieved great success by applying this method. The Taguchi method adopted experimentally to investigate the influence of parameters such as material stress, thickness and diameter of pipe on the induced stress in the chassis. The Taguchi process helps to select or to determine the optimum combination of material stress, thickness of pipes and diameter of pipe and the effect of these parameters on induced compressive stress on the chassis during the time of collision. Many researchers developed many mathematical models to optimize these parameters to get maximum induced stress in various processes.

\section{PHILOSOPHY OF THE TAGUCHI METHOD}

- Quality of product depends on the process by which it has been produced. One can improve the quality by optimizing the parameter affects the process.

- Better quality can be achieved by minimizing uncontrollable environmental factor which leads to deviation from a target.

- The cost of quality should be measured as a function of deviation from the standard and the losses should be measured system wide. 


\section{PROCEDURE AND STEPS OF TAGUCHI PARAMETERS DESIGN}

\section{Step-1: Selection of the Quality Characteristic}

There are three types of quality characteristics in the Taguchi methodology, such as smaller-the-better, larger the- best, and nominal-the-best. For example, smaller-the-better is considered, when measuring fuel consumption of fuel in automobiles or roughness in surface finish. The goal of this research was to find the effect of parameters and achieve maximum compressive stress induced during collision.

\section{Step-2: Selection of Noise Factors and Control Factors}

In this step, the controllable factors are material (M), thickness of pipe (T) and diameter of pipe (D) which was selected because these are the factors which affect the induced compressive stress. Since these factors are controllable so they are considered as controllable factors in the study? Uncontrollable factors may be the ambience temperature, Humidity, road quality and human error.

\section{Step-03: Selection of Orthogonal Array}

There are 9 basic types of standard Orthogonal Arrays (OA) in the Taguchi parameter design. Selection of arrays depends on the degree of freedom of a selected parameter. Degree of freedom of all three parameters is 6 . An $\mathrm{L}_{9}$ Orthogonal Array is selected from Appendix B, $2^{\text {nd }}$ edition, 2005, Taguchi Techniques for Quality Engineering, Philip J Ross, Tata McGraw-Hill Publishing Company limited, for this work.

An $\mathrm{L}_{9}$ Orthogonal Array is selected for this work. The layout of this $\mathrm{L}_{9} \mathrm{OA}$ is, as mentioned in Table 3.1.

Table 3.1: The Layout of $\mathrm{L}_{9} \mathrm{OA}$ Array

\begin{tabular}{|c|c|c|c|}
\hline Experiment & P1 & P2 & P3 \\
\hline 1 & 1 & 1 & 1 \\
\hline 2 & 1 & 2 & 2 \\
\hline 3 & 1 & 3 & 3 \\
\hline 4 & 2 & 1 & 2 \\
\hline 5 & 2 & 2 & 3 \\
\hline 6 & 2 & 3 & 1 \\
\hline 7 & 3 & 1 & 3 \\
\hline 8 & 3 & 2 & 1 \\
\hline 9 & 3 & 3 & 2 \\
\hline
\end{tabular}

\section{Step-4: Conducting the Experiments}

Table 3.1 illustrates the experimental settings in this study for maximum compressive stress. The parameters used in this experiment are material (three different materials), thickness of pipe (three different thicknesses) and the diameter of pipe (three different diameters). All nine analyses have been conducted on ANSYS software results of which have been observed.

\section{Step-5: Predicting Optimum Performance}

Using the aforementioned data, one could predict the optimum combination of material, thickness and diameter for maximum compressive stress induced during impact of collision. With this prediction, one could conclude that which combination will create the best result. A confirmation of the experimental design was necessary in order to verify the optimum variable combination. 


\section{Step-6: Establishing the Design by using a Confirmation Experiment}

The confirmation experiment helps to verify our prediction, particularly when small fractional factorial experiments are utilized. The purpose of the confirmation experiment in this study was to validate the optimum compressive stress induced during collision.

\section{DESIGN}

The chassis is designed, considering the factors like factor of safety - maximum load carrying capacity, force absorption capacity, required space for accessories and driver and specific dimensions.

The design of the chassis is performed by using software's ANSYS. The load distribution in the chassis should be uniform. The structural design gives the idea about the chassis.

\section{MODELING}

\section{The 3-D modelling of Chassis is created by ANSYS:}

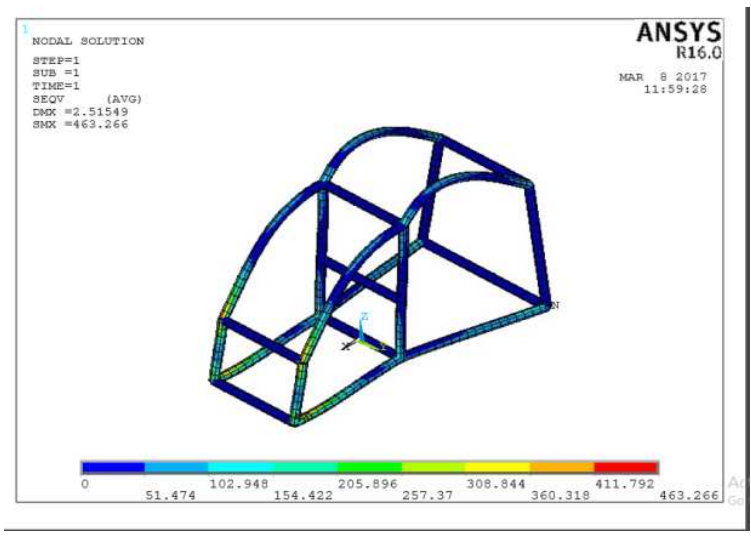

Figure 6.1: Modelling Design of Chassis on ANSYS

\section{Analysis}

The next stage after the design is an analysis of the chassis under various impact forces and overall dynamic loads applied during the race. By performing analysis, the stresses induced in the structure can be determined.

\section{Analysis of Means}

The analysis of each controllable factor is studied and the main effect of the same is obtained in table 5.4. The main effect of each factor at individual level i.e.at low, medium, high levels is equal to the mean of hardness of all experiments with the factor at the individual level.

The main effect of material on stress at various levels calculated as follows.

$$
\begin{aligned}
& M_{1}=(463.24+290.10+196.95) / 3=316.77 \\
& M_{2}=(363.93+233.11+322.42) / 3=306.27 \\
& M_{3}=(294.44+374.14+246.77) / 3=305.11
\end{aligned}
$$


The main effect of thickness on stress at various levels calculated as follows.

$$
\begin{aligned}
& \mathrm{T}_{1}=(463.24+363.93+294.44) / 3=373.87 \\
& \mathrm{~T}_{2}=(290.10+233.11+294.44) / 3=272.55 \\
& \mathrm{~T}_{3}=(196.95+322.42+246.77) / 3=255.38
\end{aligned}
$$

The main effect of depth of cuts on hardness at various levels calculated as follows.

$$
\begin{aligned}
& \mathrm{D}_{1}=(463.24+322.42+374.14) / 3=386.6 \\
& \mathrm{D}_{2}=(290.10+363.93+246.77) / 3=300.26 \\
& \mathrm{D}_{3}=(196.95+233.11+294.44) / 3=241.5
\end{aligned}
$$

Table 6.1: Results Obtained After Analysis

\begin{tabular}{|c|l|c|c|c|}
\hline \multirow{2}{*}{ Symbol } & \multirow{2}{*}{ Controllable Factors } & \multicolumn{3}{|c|}{ Hardness (HRC) } \\
\cline { 3 - 5 } & & $\mathbf{L}$ & $\mathbf{M}$ & $\mathbf{H}$ \\
\hline $\mathbf{M}$ & Material & 316.77 & 306.27 & $\mathbf{3 0 5 . 1 1}$ \\
\hline $\mathbf{T}$ & Thickness & 373.87 & 272.55 & $\mathbf{2 5 5 . 3 8}$ \\
\hline & Diameter & 386. & 300.26 & 241.5 \\
\hline
\end{tabular}

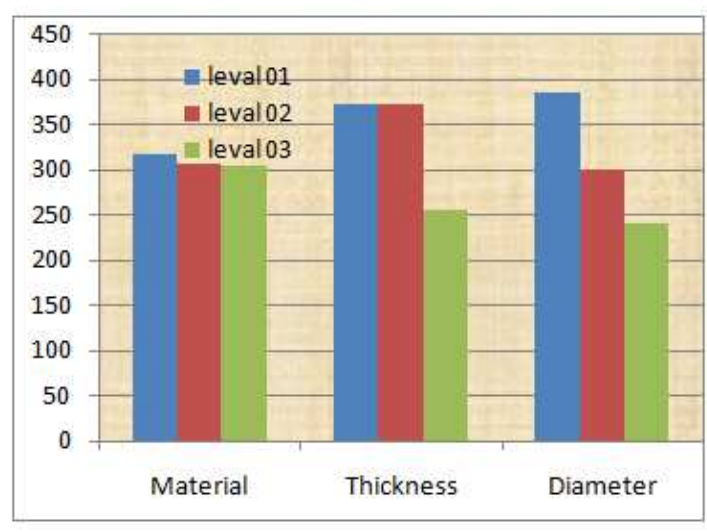

Figure 6.2: The Graphical Representation of the Result Found

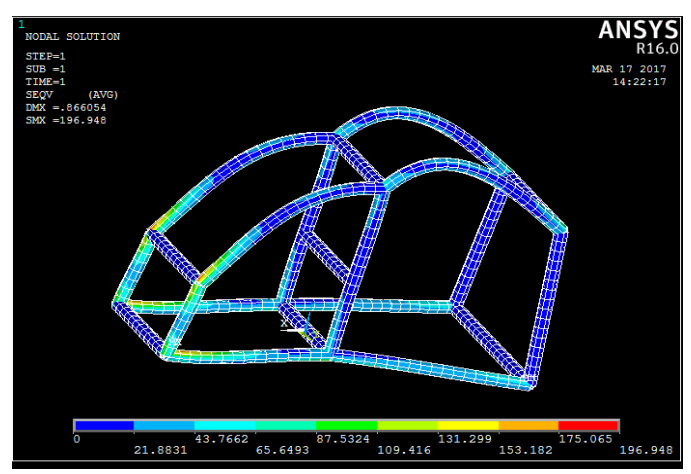

Figure 6.3: Result on ANSYS 


\section{Conclusion}

The thesis has discussed parameters and indicates that the Taguchi design of experiments is an effective way of determining the optimal combination of parameter.

The outcome of the calculation and formulation of the optimization of Taguchi method, are summarized.

An application of Taguchi method for optimizing the design

Table 6.2: The Outcome of Calculation by Taguchi Method

\begin{tabular}{|l|c|c|}
\hline \multicolumn{1}{|c|}{ Results } & $\begin{array}{c}\text { Induced compressive } \\
\text { stress by ANSYS }\end{array}$ & $\begin{array}{c}\text { Induced compressive stress by } \\
\text { Mathematical formula }\end{array}$ \\
\hline Level & $\mathrm{M}_{3}+\mathrm{T}_{3}+\mathrm{D}_{3}$ & $\mathrm{M}_{3}+\mathrm{T}_{3}+\mathrm{D}_{3}$ \\
\hline $\begin{array}{l}\text { Induced } \\
\text { stress (MP) }\end{array}$ & 196.948 & 197 \\
\hline
\end{tabular}

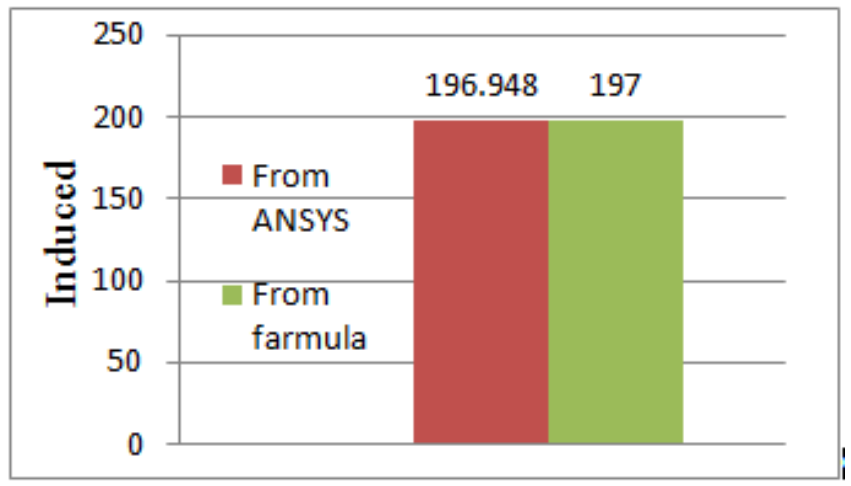

Figure 6.4: Graphical Representation of the Outcome

\section{CONCLUSIONS}

From the response graph plotted between parameters, it is observed that there is a decrease in induced stress as the yield stress, Thickness of the pipe and diameter of pipe are increased

From response table and graph, observational findings are illustrated as follows.

- $\quad$ Level III for Material = lower induced stress indicated as the optimum situation in terms of the mean value.

- Level III for Thickness of pipe = lower induced stress indicated as the optimum situation in terms of the mean value.

- Level III for Diameter of pipe = lower induced stress indicated as the optimum situation in terms of the mean value.

The result obtained from the confirmation experiments reveals that the Taguchi method has provided the best prediction for the response value By the application of Mathematical regression modelling researcher has found out the empirical formula, which shows the relation between these three factors i.e. yield stress, thickness, diameter. By the use of this formula, we can find out the value of stress at the time of impact at any given combination between a given range. 


\section{Future Scope}

However, the research work can be extended as a future scope by taking various other factors and level of combinations. In this way, one can design and analyze the chassis with different aspects to make safe and economic.

\section{REFERENCES}

1. Riley William B, and George Albert R. "Design Analysis and testing of a formula SAE Car Chassis" SAE international technical Paper series, Volume, Issue ,Page no,2002

2. Rahman Roslan Abd, Tamin Mohd Nasir and Kurdin Ojo "Stress Analysis of heavy Duty truck chassis as a preliminary data for its Fatigue life prediction using FEM” journal Mechanical, page No. (76-85), Dec. 2008.

3. Tebby Steven, Esmail zadeh Ebrahim and Barari Ahmad "Methods to determine torsion Stiffness in an Automotive Chassis." Computer Added Design and application, page no. (67-75),2011

4. Renuke Pravin "A Dynamic analysis of a Car Chassis" International journal of Engineering Research and application (IJERA), volume - 02, Issue-06, page no. (955-959), Nov. - Dec 2012

5. Agarwal Monika S. and Razik Md. "A Review on study of analysis of chassis" International Journal of modern Engineering Research (IJMER), volume-03,Issue -02, Page no-(1135-1138), March-April 2013

6. Patil Hemant B, Kachave Sharad D. and Deore Eknath R. "Stress analysis of Automotive Chassis with various thicknesses" IOSR Journal of Mechanical and Civil Engineering (IOSR - JMCE), Volume- 06, Issue-01, page no. (44-49), Mar.- Apr. 2013

7. Dr. Rajappan R. and Vivekanandhan M. "Static and modal Analysis of Chassis by using Fea" The International Journal of Engineering and Science (Ijes), Volume-2, Issue-2, page no. (63-67), 2013

8. Moaaz Ahmad O. and GhazalyNouby M. "A Review of the Fatique Analysis of heavy Duty Truck frames" American Journal of Engineering Research (AJER), Volume-03, Issue-10, page no.-(01-06), 2014

9. M. P. Prajwal Kumar, MurlidharanVivek and Madhusudhana G. "Design and Analysis of a tubular space frame Chassis of high performance race car." International Journal of research in Engineering and Technology, volume - 03, Issue - 02, page no. (497-501), Feb. 2014

10. Jogi N. G., Take Akshay P. and Aftab Sheikh M. "Review work on analysis of F1 Car frame using ANSYS" International Journal of research in Engineering and technology, Volume-03, Issue-04, page no. (215-217), Apr.2014

11. Ghodvinde Kiran and Wankhade S. R. "Structural stress analysis of an automotive vehicle Chassis." International Journal on Mechanical Engineering and Robotics (IJMER), Volume - 02, Issue -06, page no. (2321-2325), June -2014

12. Shiva kumar M. M. and Nirmala L. "Fatigue Life Estimation of Chassis frame FESM Bracket for Commercial Vehicle." Volume-03, Issue-08, page no. (441-447), Aug-2014

13. Moaaz Ahmad O. and Ghazaly Nouby M. “Finite Element Stress Analysis of truck Chassis using ANSYS: Review." International journal of advances in Engineering \& Technology, Volume -07, Issue -05, page no. (1386-1391), Nov.-2014

14. Gadagottu Indu and Mallikarjun M. V. "Structural analysis of heavy vehicle Chassis using honey comb Structure." International Journal of Mechanical Engineering \& Robotics Research, Volume-04, Issue, page no. (173-172), Jan.-2015

15. Patil Suraj B. and Josi Dinesh G. "Structural Analysis of Chassis: A Review" international Journal of Research in Engineering Technology, Volume-04, Issue-04, page no. (293-296), Apr.-2015

16. Agrawal Monika S. "Finite Element Analysis of truck Chassis frame” Volume-02, Issue-03, page no.(1949-1956), June-2015 
17. Patil Kamlesh Y. and Deore Eknath R. "Stress Analysis of Ladder Chassis with Various Cross Sections "IOSR journal of Mechanical \& civil Engineering (IOSR-JMCR), Volume -12, Issue-04, page no.(111-116), july-Aug 2015

18. Mr. Birajdar M.D. and Prof. Mule J.Y. “Design Modification of Ladder Chassis Frame” International Journal of Science Engineering and Technology Research, Volume- 04, Issue-10, page no. (3443-3449), Oct-2015

19. Dubey Ashutosh and Dubedy Vivek "Vehicle Chassis Analysis: Load cases and Boundary Condition for Stress Analysis. 